\title{
Design, Development and Numerical Analysis of Honeycomb Core with Variable Crushing Strength
}

\author{
Shabnam Sadeghi Esfahlani, Hassan Shirvani, \\ Ayoub Shirvani, Habtom Mebrahtu and Sunny Nwaubani
}

Science and Technology, Faculty of Engineering and Built Environment, Bishop Hall Lane,

Anglia Ruskin University, Bishop Hall Lane, Chelmsford, Essex, United Kingdom

Received 2012-11-21, Revised 2012-12-03; Accepted 2013-03-11

\begin{abstract}
A honeycomb core with half-circular cut-away sections at the spine (the adjoining cell walls) is designed and developed and numerically tested under axial dynamic load condition. The parametric study is invoked to identify the effect of various circular cut-away dimensions. In one embodiment a half-circular shaped cuts are removed from the top of the cell where the cell is impacted and its radius decreases toward the trailing edge of the cell. Numerical (FE) analysis was performed using explicit ANSYS/LS-DYNA and LSDYNA codes to investigate the crushing performance, where impact angles $30^{\circ}$ and $90^{\circ}$ was combined with velocity of $5: 3 \mathrm{~m} / \mathrm{sec}$. The crushing strength and internal energy absorption of the modified honeycomb cores with cut-away sections are then monitored to define the design parameters. The representative Ysection (axisymmetric model) is used for numerical analysis which simulates the honeycomb crushing performance. The numerical results of these innovative models show cyclic buckling effect in which crushing strength increases linearly as the rigid wall passes through. The FE results are validated with corresponding published experiments of the original unmodified honeycomb core (without cut-away).
\end{abstract}

Keywords: Circular Cut-Away Sections, Crashworthiness, Cut-Away at Spine, Energy Absorption, Compressive Loading, Crushing Strength

\section{INTRODUCTION}

Shell structures are widely used in engineering applications for their high strength to weight ratio and energy absorption in axial compression. In vehicle crash tests, moving or stationary deformable barriers made of aluminium honeycombs are used to simulate second crashed vehicle, Aktay et al. (2008). During the compression of cellular structures, the kinematic energy of a moving mass transforms into the energy of plastic deformation. This energy is absorbed through the large compressive stroke, therefore buckles in a progressive mode. The energy absorption and crushing strength characteristic of these structures are influenced by the mechanical properties, the thickness, the geometric configuration and also the mass of the cell walls.
Numerical, experimental and analytical investigation of cell walls etching and thinning process of hexagonal honeycomb was reported by Ogasawara et al. (2010). The etching of the honeycomb was conducted in order to obtain a crush strength that is increasing linearly during the time. The crush behaviour of aluminium honeycomb specimens under (combined) multi direction loads was conducted by Hong et al. (2006). They showed that the energy absorption rate depends on the ratio of the shear stress to the compressive stress and on the in-plane orientation angle. Laterally compressive response of honey comb panels have also been studied by Wilbert et al. (2011). The honeycomb panels are laterally compressed quasi-statically between rigid platens from the initial elastic regime to a fully crushed state.

Corresponding Author: Shabnam Sadeghi Esfahlani, Science and Technology, Faculty of Engineering and Built Environment, Bishop Hall Lane, Anglia Ruskin University, Bishop Hall Lane, Chelmsford, Essex, United Kingdom 
The regular shapes of cellular structures are triangle, square and hexagonal shape columns and are known as honeycomb cellular structures with the edge connectivity of six, four and three respectively. As the edge connectivity increases the crush strength increases but the efficiency of these structures decreases, given that more solid are used to enclose the same pore volume Gibson and Ashby (1999). Cellular structures with cutaway sections from the cell walls is an effective process in that honeycomb core has less mass and at the same time same energy absorption.

In this study the patented honeycomb core with circular cut-away sections at the spine of each cell is investigated. Parametric study is performed to analyse the effect of dimension of cut-away sections. FE simulation of the cells with cut-away sections were performed using 90 and $30^{\circ}$ impact angle. The parametric analysis was carried out using numerical analysis to improve the energy absorption capability, assess model efficiency and achieve variable crushing load. The results are compared with the original honeycomb core (without cut-away) and great performance was achieved.

\subsection{Aluminium Honeycomb Characteristics}

Aluminium honeycombs have various material requirements and cell size, generally speaking stronger materials do not always result in stiffer blocks. The strength of cellular structures in compression is significantly influenced by mechanical properties of the material, thickness of the cell walls, relative density, mass and also the geometric configuration of cell. Therefore, it is valuable to manage the strength and buckling performance of them by effective extra procedures which are environmental friendly.

The in-plane sketch of hexagonal honeycomb in Fig. 1a shows that a closed hexagonal cell is made of six representative Y-sections. The out-of-plane sketch of this $\mathrm{Y}$-section is plotted in Fig. 1b that is used for Finite Element simulation. Figure 1c shows the honeycomb core with circular cut-away sections at spines. This energy absorber devices are crushed to a certain distance, the energy absorption to this point is significant until reaches the densification point.

In this investigation the numerical simulation of a Drop-hammer crash test apparatus was utilized which carries a mass of $72 \mathrm{~kg}$ with a speed of $5240 \mathrm{~mm} / \mathrm{sec}$. The cross sectional properties of regular hexagonal models are cell thickness $\mathrm{T}_{1}$ and $\mathrm{T}_{2}=2 \mathrm{~T}_{1}$, cell size $\mathrm{S}$ and angle $\theta$ between side lengths $\mathrm{w}_{1}$ and $\mathrm{w}_{2}$. The geometrical and mechanical properties of simulated models are depicted in Table 1. For the axisymmetric nature of honeycomb representative Y-section is modelled. According to cross sectional area of simulated models, the mass of impacted loads is $0.15 \mathrm{Kg}$ with the velocities set to $5300 \mathrm{~mm} / \mathrm{sec}$ and test duration is $\mathrm{t}=0: 04 \mathrm{sec}$. Two rigid walls are defined one performs as a support and the other is a moving wall to simulate the drop hammer.

In this study explicit finite element codes, ANSYS/LS-DYNA and LS-DYNA are used to simulate the non-linear dynamic loading of this hexagonal aluminium honeycomb. ANSYS/LS-DYNA is utilized for parametric study that parametrize the geometry of cell and cut-away for various simulations. In this research plastic-kinematic-hardening material with fournode [Belytscho-Tsay] shell element formulation and AUTOMATIC-SINGLE-SURFACE contact is defined between parts. Strain rate characteristic is neglected in numerical simulation, Sadeghi-Esfahlani et al. (2011). Models are meshed with mapped mesh and quadrilateral shaped elements. Number of elements and division of the lines for all the models are identical for comparison.

In order to evaluate the performance of simulated energy absorbing devices internal energy absorption, mean crushing stress and stroke efficiency (effective crushing distance) are employed to assess the performance of models, Zhang et al. (2009). The energy absorbed during axial crushing is calculated by integration of the force $\mathrm{F}$ over displacement $\gamma$ curve Equation 1:

$$
\mathrm{E}=\int_{0}^{\gamma} \mathrm{F}(\gamma) \mathrm{d} \gamma
$$

The mean crushing strength is calculated by the ratio of compressive load $\mathrm{F}$ to the cross sectional area of the structure A, as following Equation 2:

$\sigma=\frac{\mathrm{F}}{\mathrm{A}}$

In this study the crush strength is obtained from the ratio of force created by the rigid wall in numerical analysis to the cross sectional area of $\mathrm{Y}$-section $\mathrm{A}=$ 129.9 $\left(\mathrm{mm}^{2}\right)$ (dashed lines in Fig. 1).

\subsection{Finite Element Analysis and Results of Y- Section Cell with Circular Cut-Away Sections at the Spine}

The buckling performance of aluminium honeycomb cells with half-circular cut-away sections from the spine has been studied. To investigate the performance of cellular structures anisotropic elastic properties, out-ofplane crushing response and energy absorption in numerical analysis are considered. Numerical simulation and mesh sensitivity analysis was conducted. Courser mesh resulted in higher internal energy absorption compared to the course mesh but does not have significant effect on crush strength. 


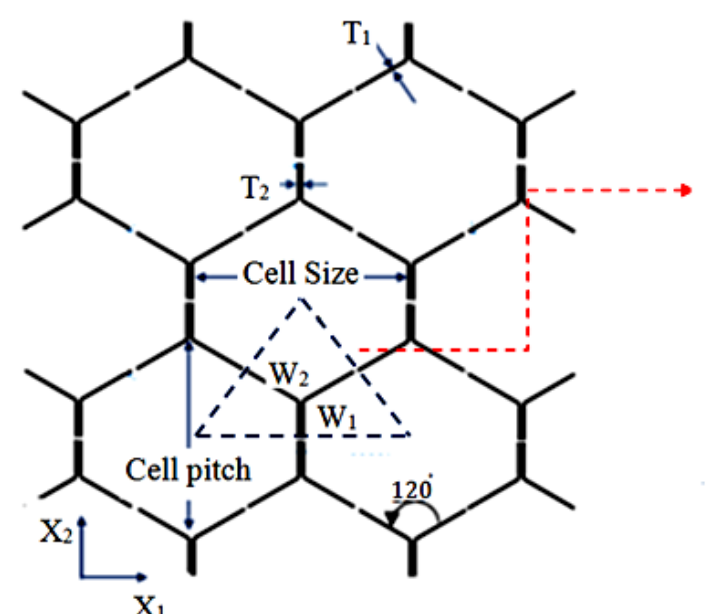

(a)

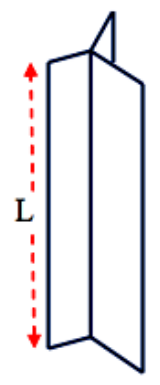

(b)

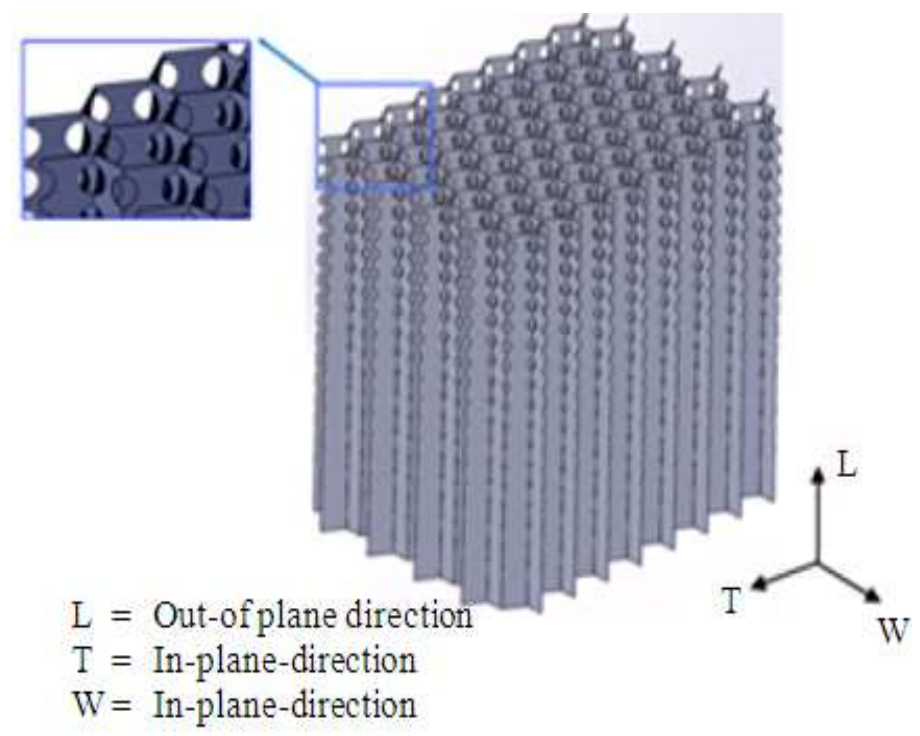

(c)

Fig. 1. General characteristic of $2 \mathrm{D}$ cross section (a), 3D Y-section (b) and regular hexagonal honeycomb core with cut-away at Spine (c)

The parametric investigation is executed in order to examine the variability of crushing load and strength with respect to different dimensions. Half- circular sections are removed from the Spine of Y-section with various radius and number of cuts along the axial direction. The dimension of the radius of cuts was decreased linearly from impact edge toward the end of the cell. This innovative process enabled us to achieve a crushing strength that increases linearly as it buckles. Figure 2 shows the FE models and the dimension of cut- away sections. Six different combination number of cuts with different dimensions are considered. The radius of cuts decreased toward the trailing edge. The radius of Sample 0 started from $\mathrm{r}=3: 0(\mathrm{~mm})$ and decreased linearly by the value of 0:02 (mm). Sample 1 has larger cut-away radius that started from larger diameter, $r=3: 8$ $(\mathrm{mm})$ and again decreased linearly by the value of 0:02 (mm) toward the end. Cut-away sections in Sample 2 happened from radius $r=3: 4 \quad(\mathrm{~mm})$ and reduces by the value of 0:03 $(\mathrm{mm})$. 
According to the results obtained from these three models Sample 3, 4 and 5 are created. Cut-away sections of cells with started radius $r=3: 4$ and 3:8 $(\mathrm{mm})$, resulted in crushing load near zero for quietly long time. Therefore, other three samples are combination of radius started from 3:0 $(\mathrm{mm})$ and decreased linearly by the value of $0: 2(\mathrm{~mm})$.

The progressive crushing of simulated samples are depicted in Fig. 3. The progressive buckling stages commences from preliminary linear elastic regime from which the first buckle initiates to the inelastic progressive folding and densification of the cell. Cell collapse ends once the opposite cell walls come to contact each other. The stress in all samples is increasing progressively as the cell buckles by the crushing length that is controlled by the diameter of circular cuts and number of them. The crushing stress in all models reach the same level equal to the crushing load of the original model (without cut-away).

The crushing stress-displacement of samples is illustrated in Fig. 4. The buckling starts from a peak load that is a elastic to plastic mode, then followed by zero load. The load increases gradually depend on the diameter and number of cut-away sections. Sample 1 has largest circular diameters therefore at the beginning of buckling, the crushing strength is low and suddenly rises to its highest level which is around 47:5 (N). Crush stress in Sample 0 smoothly increases and is higher than Sample 1. In Sample 2 the diameter decreases by the value 0:03 $(\mathrm{mm})$ from the radius $r=3: 4(\mathrm{~mm})$. This sample's crush stress shows as the difference between consecutive diameters increases the small peak and dip loads during the buckling augments.

Table 1. Geometrical and mechanical parameters of representative for FE simulation

\begin{tabular}{lrll}
\hline Geometrical parameters of Y-section & Aluminum alloy A3003 & \\
\hline $\mathrm{S}(\mathrm{mm})$ & 19.050 & Young modulus & $\mathrm{E}=6.89 \mathrm{e} 4 \mathrm{MPa}$ \\
$\mathrm{T}_{1}(\mathrm{~mm})$ & 0.063 & Passion ratio & $\mathrm{v}=0.33$ \\
$\mathrm{~T}_{2}(\mathrm{~mm})$ & 0.126 & Yield stress & $\sigma_{\mathrm{y}}=220 \mathrm{MPa}$ \\
$\mathrm{W}_{1}(\mathrm{~mm})$ & 4.000 & Tangent modulus & $\mathrm{E}_{\mathrm{t}}=450 \mathrm{MPa}$ \\
$\mathrm{W}_{2}(\mathrm{~mm})$ & 5.500 & Density & $\rho=2.95 \mathrm{e}-6 \frac{\mathrm{kg}}{\mathrm{mm}^{3}}$ \\
$\mathrm{~L}(\mathrm{~mm})$ & 150.000 & & \\
$\theta$ & $120^{\circ}$ & & \\
\hline
\end{tabular}

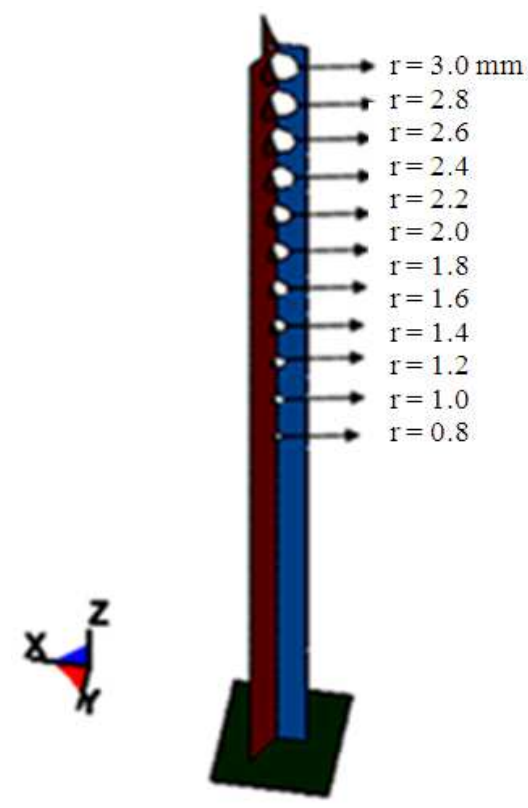

Sample 0

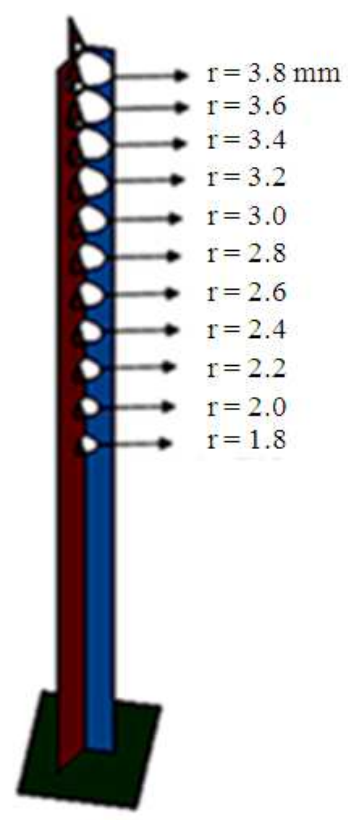

Sample 1

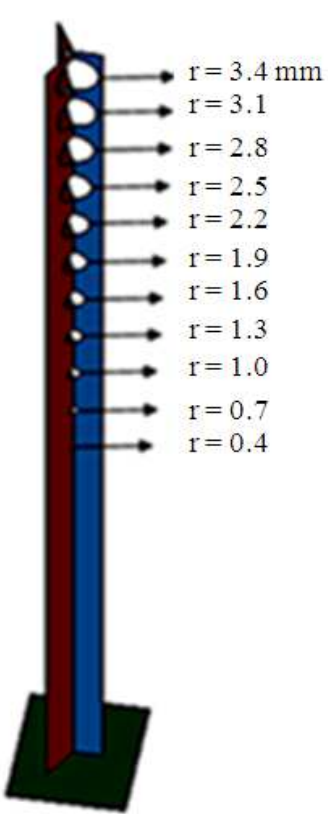

Sample 2 
Shabnam Sadeghi Esfahlani et al. / American Journal of Engineering and Applied Sciences 6 (1): 8-19, 2013

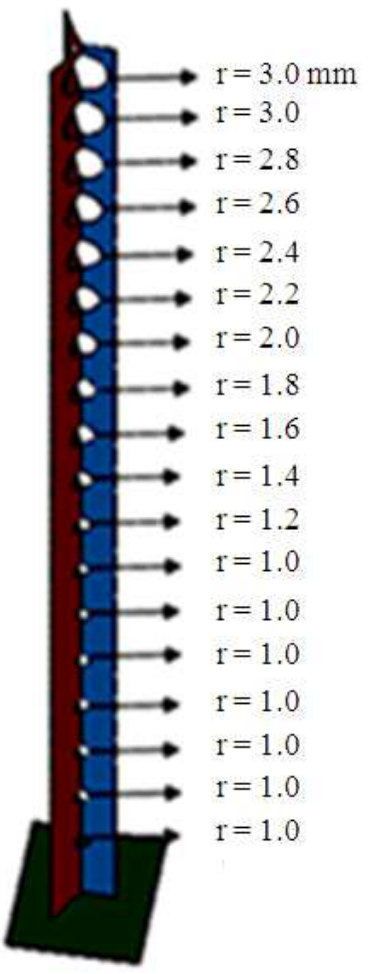

Sample 3

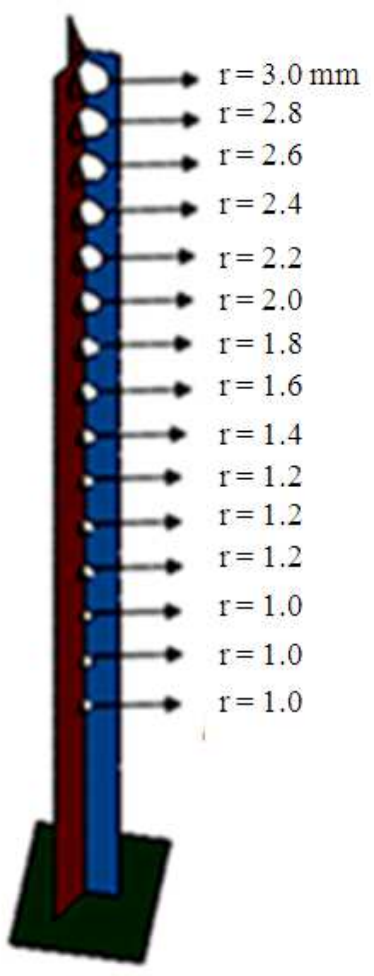

Sample 4

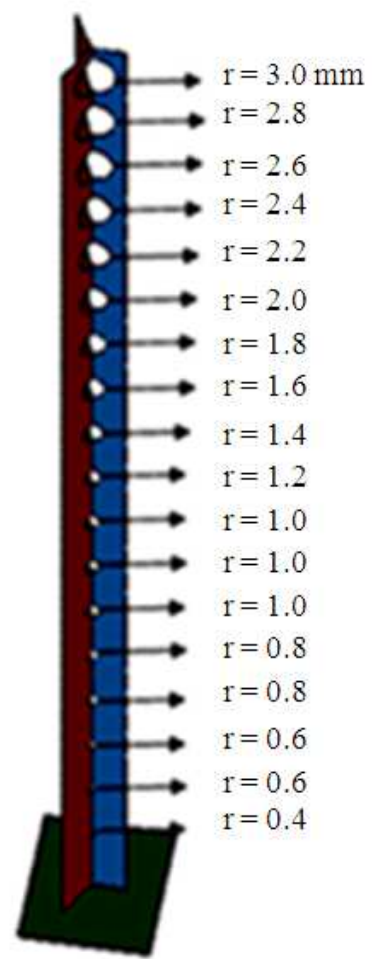

Sample 5

Fig. 2. Circular cut-away sections with various radius at the spine of representative model

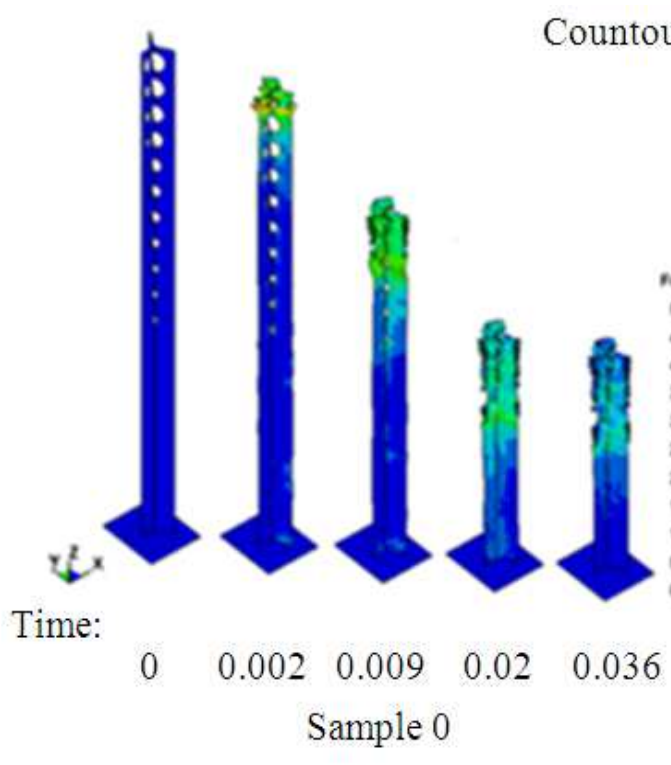

urs of effective stress

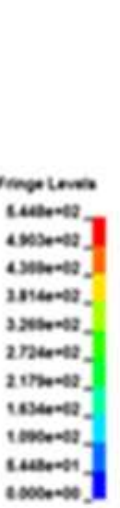

Time:

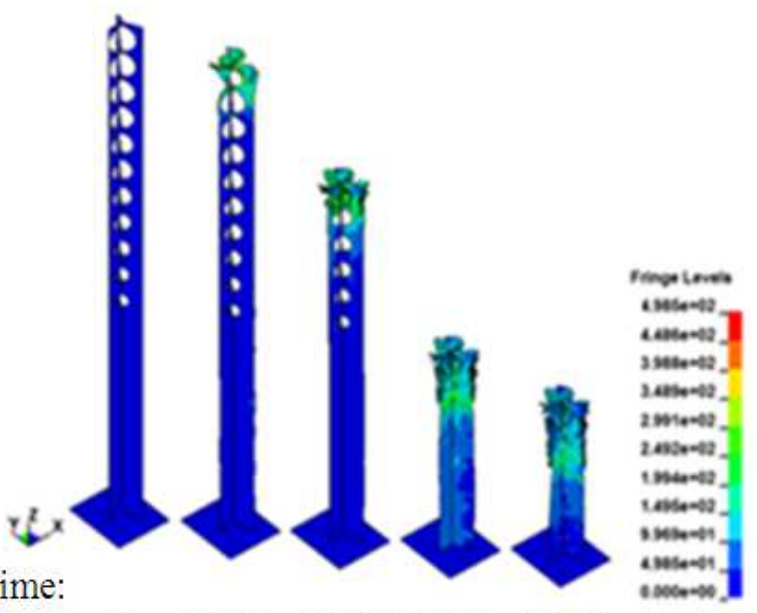

Sample 1 

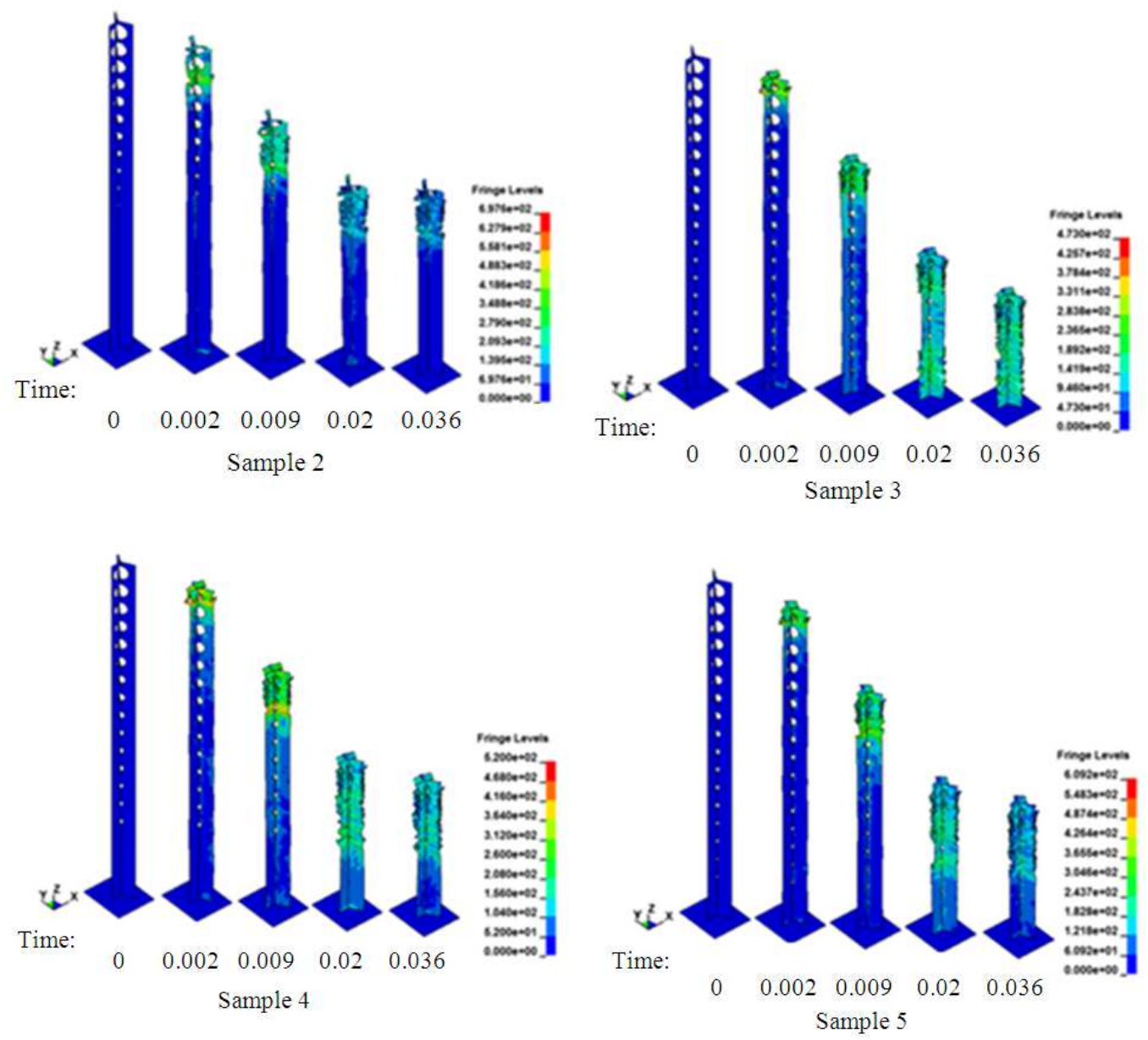

Fig. 3. Progressive crushing of samples with cut-away at Spine

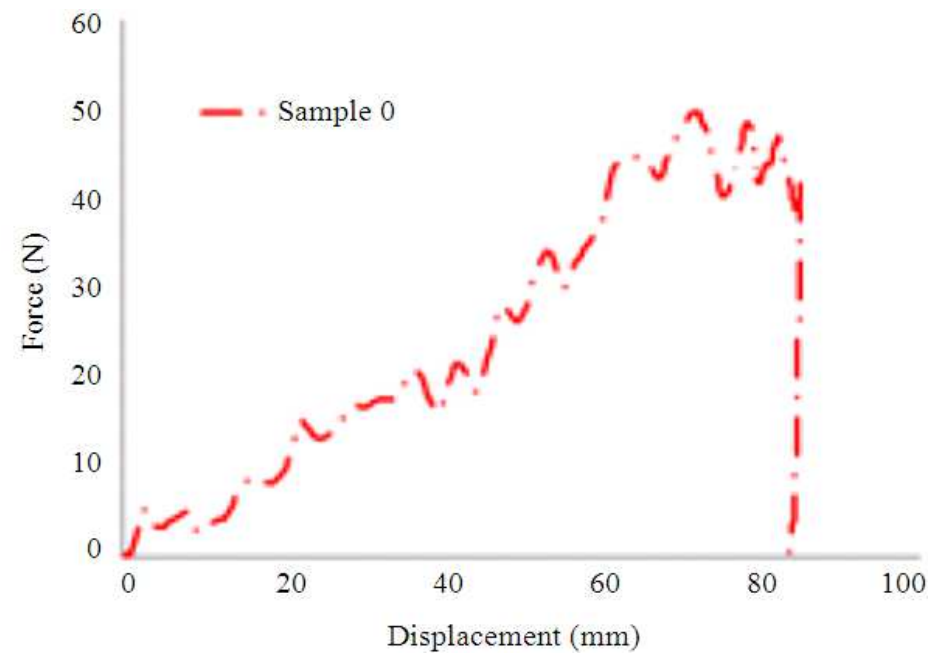


Shabnam Sadeghi Esfahlani et al. / American Journal of Engineering and Applied Sciences 6 (1): 8-19, 2013
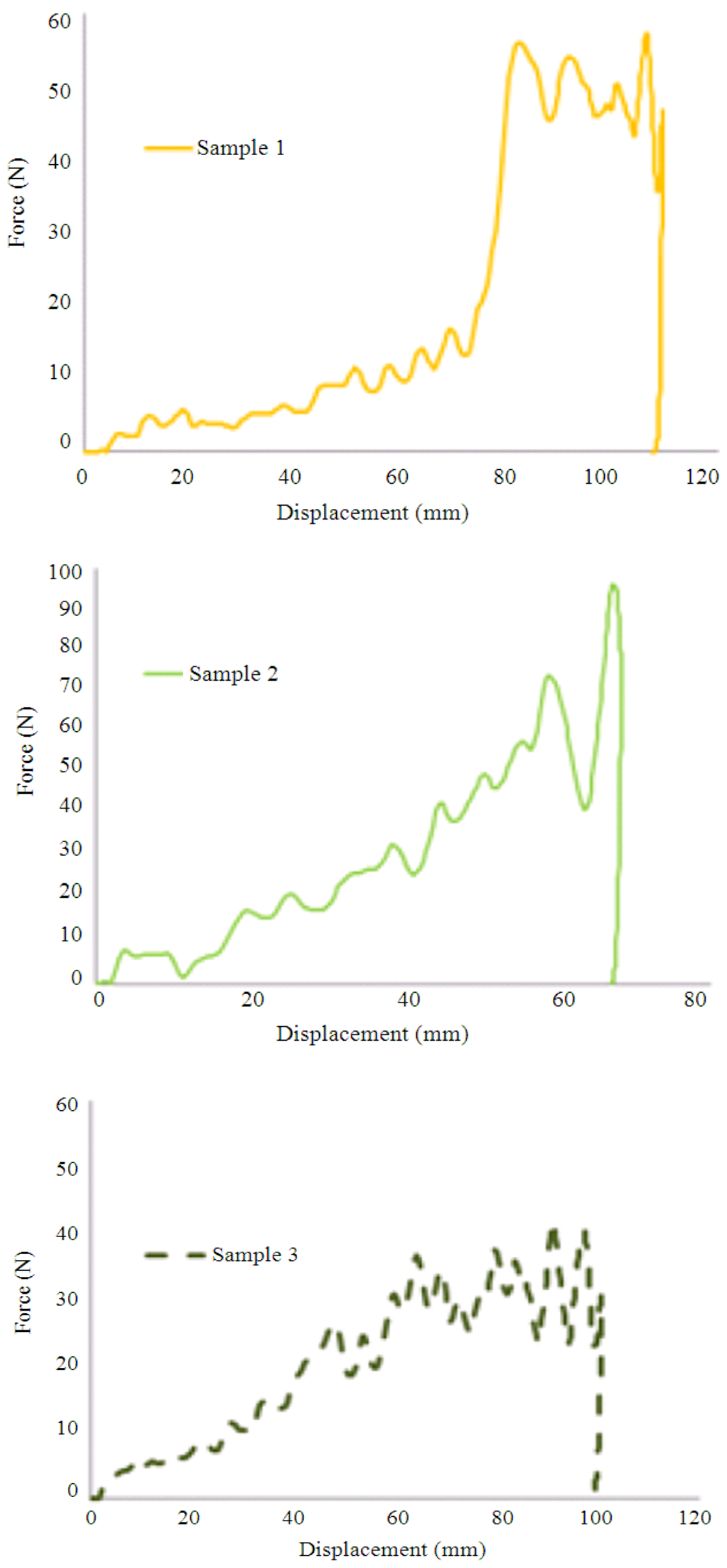

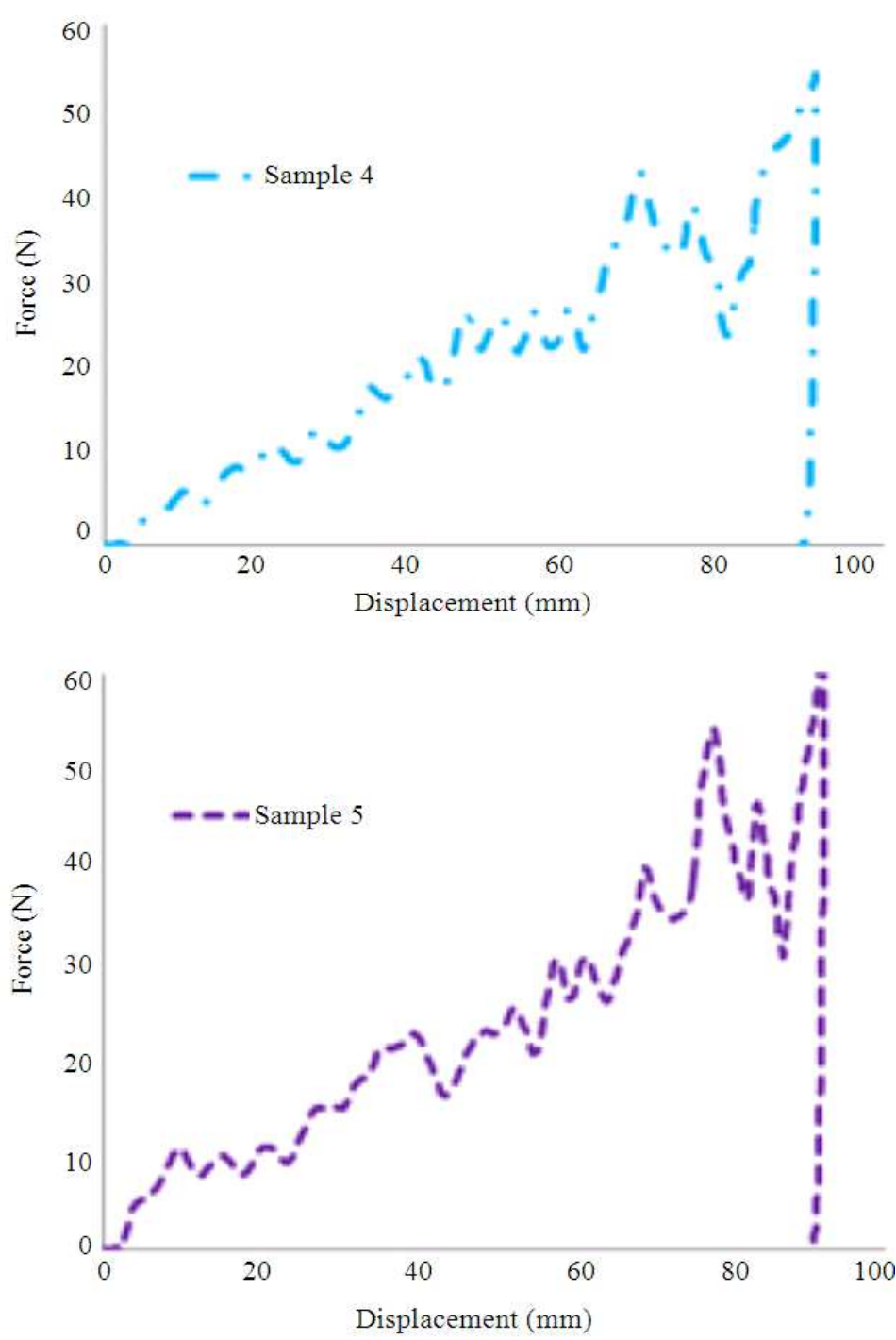

Fig. 4. Filtered load-displacement curve of cut-away at Spine

Sample 3 has cut-away sections all the way to the bottom of cell therefore its crushing load is lower than others and is around $32(\mathrm{~N})$. Sample 1 and Sample 3 has maximum crush distance compared to other samples.

Sample 4 has the same number of cut-away sections and diameters but with different arrangement. These changes are reflected in its crush stress and effective crushing load performance. In Sample 5 cuts are all the way through the cell and decreases by the value 0:02 (mm). The crush stress of this sample increases by its displacement.

FE simulations of samples are carried out in which cells are subjected to horizontal and oblique loads.
The results of this investigation are illustrated in Fig. 5. The energy absorption characteristics such as internal energy and effective crushing are higher when samples are subjected to $30^{\circ}$ loading angle compared to horizontal loading $90^{\circ}$.

The crush strength of honeycombs with cut-away at spine is potted in Fig. 6. It shows that the buckling of thin walled honeycombs with cut-away sections star by appearing lobes. Then crushing strength oscillates around a value which is rising by time. This oscillation consists of local peaks and bumps around the mean crush strength. As the lobes close up the cell densifies and becomes stiffer until buckling stops. 
Shabnam Sadeghi Esfahlani et al. / American Journal of Engineering and Applied Sciences 6 (1): 8-19, 2013
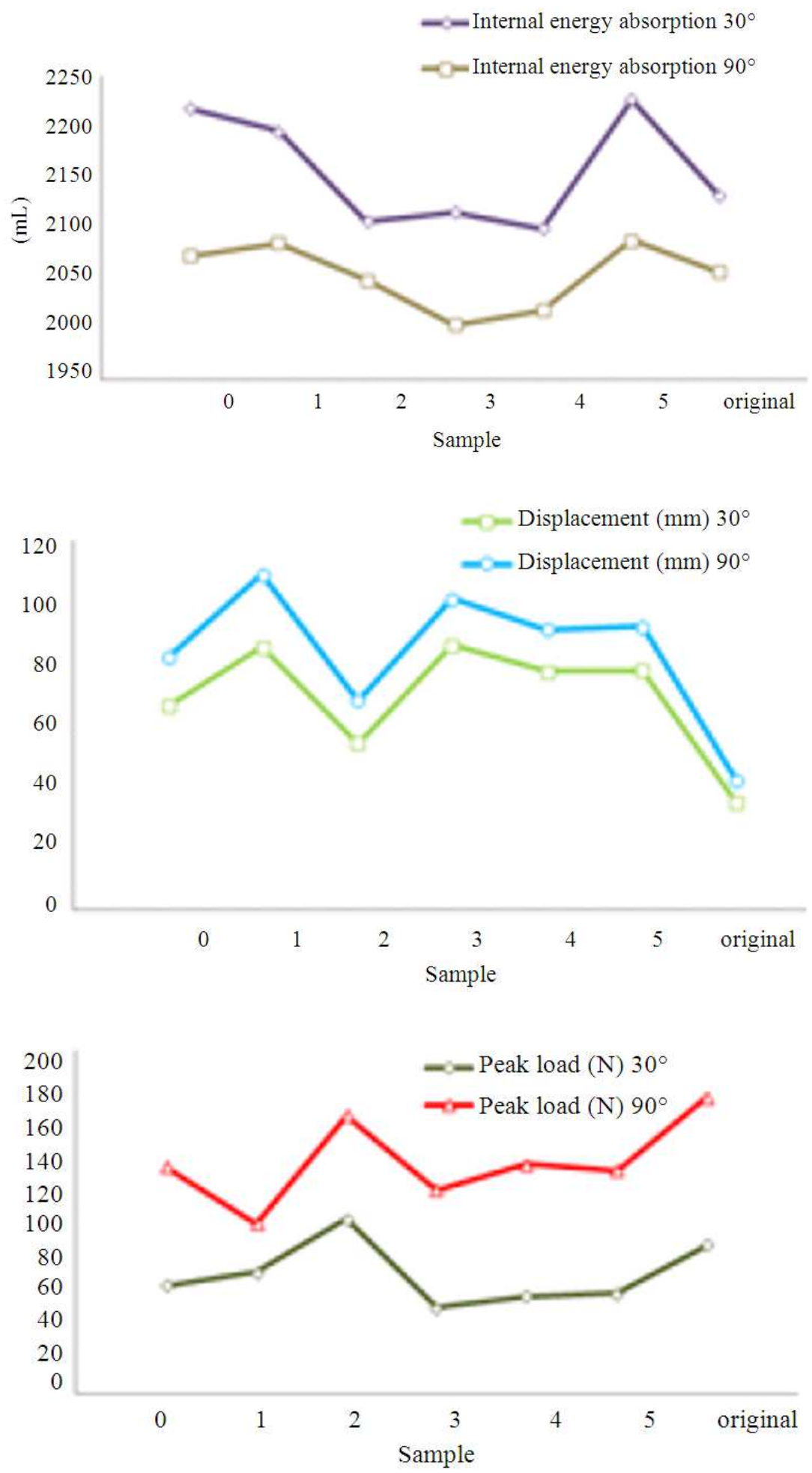

Fig. 5. FE results of samples with impact angles $30^{\circ}$ and $90^{\circ}$ 
Shabnam Sadeghi Esfahlani et al. / American Journal of Engineering and Applied Sciences 6 (1): 8-19, 2013
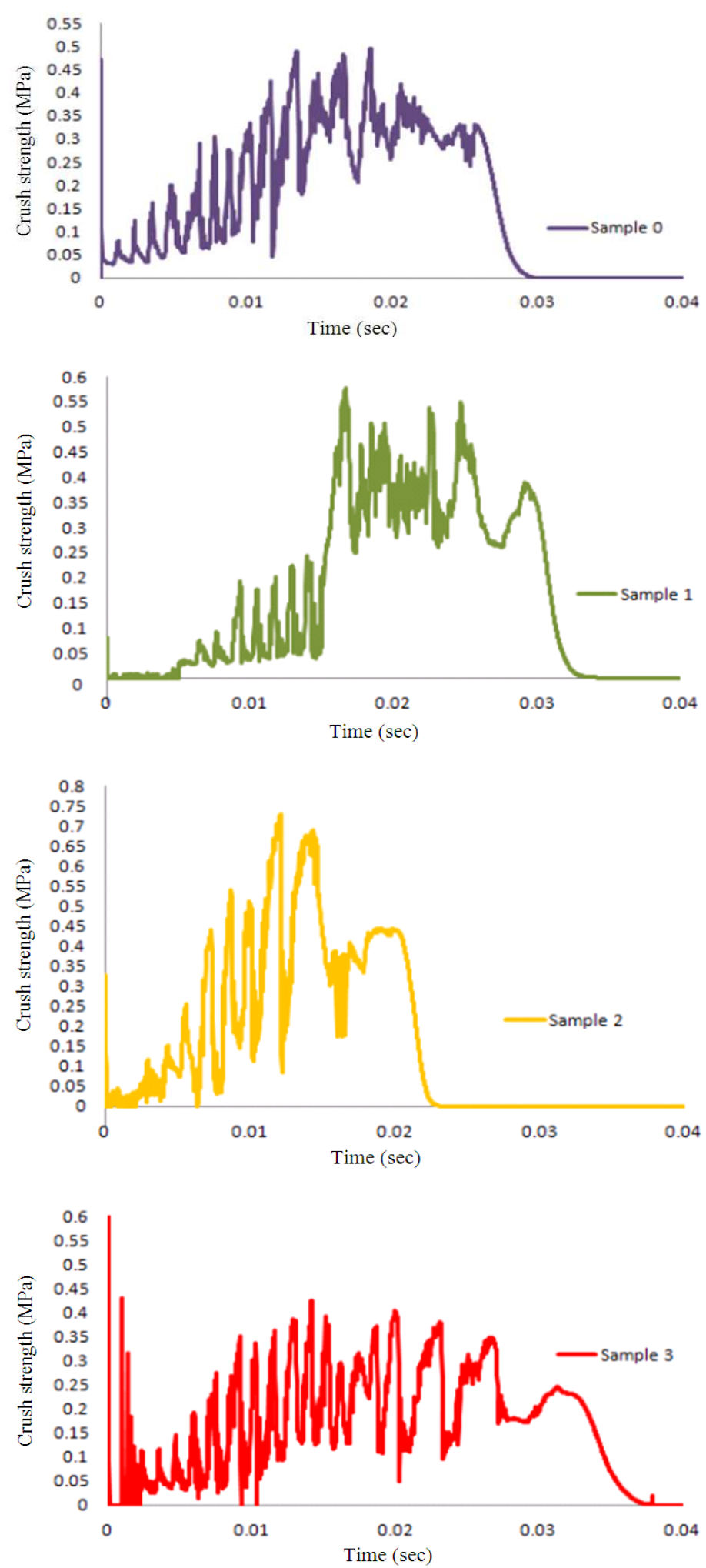

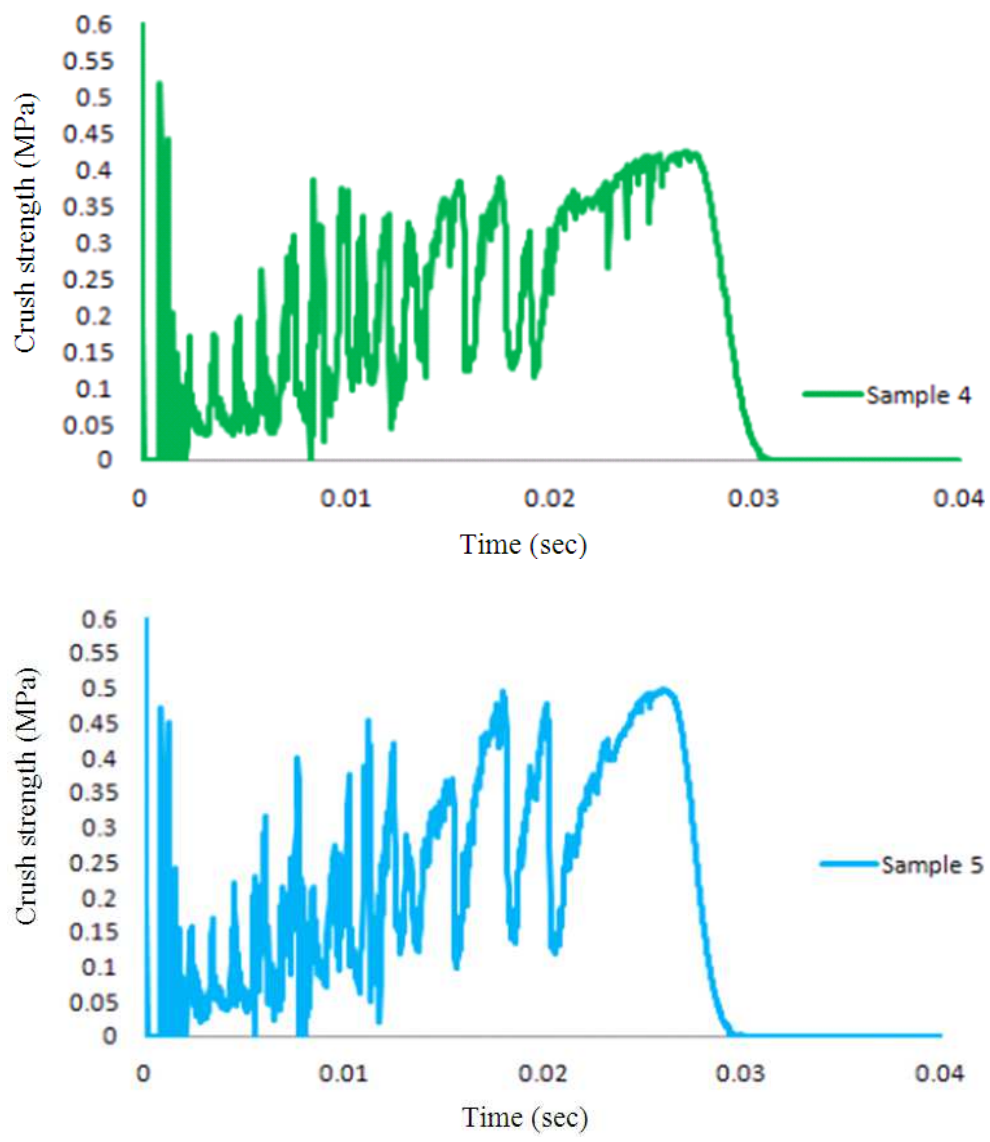

Fig. 6. Crush strength performance of honeycomb core

\section{CONCLUSION}

Aluminium honeycombs with circular cut-away sections from their spines were investigated numerically while was subjected to horizontal and oblique out-ofplane loading. Circular sections are removed from the spinal column (wall joint) of each representative Ysection this process results in cells with variable crush strength in the axial direction commercially; this can replace the acid etching process. It is clean, environmental friendly and easy to manufacture and avoids air enclose in honeycomb cells. The parametric studies of circular cut-away sections were performed to study the effect of diameter of circles on variability of crushing strength and stress of cells. The preliminary geometric characteristics are kept constant as original model for comparative study. Half circular cuts were removed from the spine of representative FE model where the radius of these circles reduced linearly from the impact edge of cell toward the bottom. This process resulted in crushing strength that is rising as the moving wall travels. The results showed that cycling buckling characteristic increases as the cuts continued toward the bottom of cells. For the cell size $\mathrm{w}_{1}=4(\mathrm{~mm})$, the circular cuts with radius $r=3: 4$ and $3: 8 \mathrm{~mm}$, result in crush strength close to zero. It was suggested that for having a honeycomb core with smoothly increasing crush strength Sample 0 with starting radius $r=3: 0 \mathrm{~mm}$ is the best choice. Cells with cut all the way through the cell have longer crush distance.

\section{REFERENCES}

Aktay, L., A. Johnson and B. Kroplin 2008. Numerical modelling of honeycomb core crush behaviour. Eng. Fracture Mech., 75: 2616-2630. DOI: 10.1016/j.engfracmech.2007.03.008

Gibson, L.J. and M.F. Ashby, 1999. Cellular Solids: Structure and Properties. 2nd Edn., Cambridge University Press, Cambridge, ISBN-10: 0521499119, pp: 532. 
Hong, S., J. Pan, T. Tyan and P. Prasad, 2006. Quasistatic crush behavior of aluminum honeycomb specimens under compression dominant combined loads. Int. J. Plasticity, 22: 73-109. DOI: 10.1016/j.ijplas.2005.02.002

Ogasawara, N., N. Chiba, E. Kobayashi and Y. Kikuchi, 2010. Crushing strength of aluminum honeycomb with thinning cell wall. J. Solid Mech. Mater. Eng., 4: 1338-1345. DOI: 10.1299/jmmp.4.1338

Sadeghi-Esfahlani, S., H. Shirvani, S. Nwaubani and A. Shirvani, 2011. Design attributes for geometry optimization process of thin walled honeycomb structures. Proceedings of the International Design Engineering Technical Conferences and Computers and Information in Engineering Conference, Aug. 28-31, ASME, Washington, DC, USA., pp: 899-908 DOI: 10.1115/DETC2011-47080
Wilbert, A., W. Jang, S. Kyriakides and J. Floccari, 2011. Buckling and progressive crushing of laterally loaded honeycomb. Int. J. Solids Struct., 48: 803816. DOI: 10.1016/j.ijsolstr.2010.11.014

Zhang, X., G. Cheng and H. Zhang, 2009. Numerical investigations on a new type of energy-absorbing structure based on free inversion of tubes. Int. J. Mech. Sci., 51: 64-76. DOI: 10.1016/j.ijmecsci.2008.11.001 